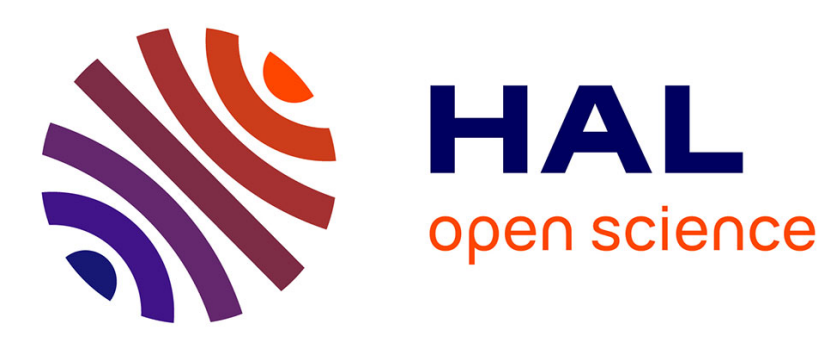

\title{
The Role of Communicators in Innovation Clusters
}

\author{
Bettina Blasini, Rani Jeanne Dang, Tim Minshall, Letizia Mortara
}

\section{To cite this version:}

Bettina Blasini, Rani Jeanne Dang, Tim Minshall, Letizia Mortara. The Role of Communicators in Innovation Clusters. Pfeffermann, N., Minshall, T., \& Mortara, L. Strategy and Communication for Innovation, An Integrative Management View for Start-ups, Companies and Collaborative Networks in the Open Innovation Economy, Springer, p. 119-138, 2013. halshs-00929782

\section{HAL Id: halshs-00929782 \\ https://shs.hal.science/halshs-00929782}

Submitted on 19 Sep 2014

HAL is a multi-disciplinary open access archive for the deposit and dissemination of scientific research documents, whether they are published or not. The documents may come from teaching and research institutions in France or abroad, or from public or private research centers.
L'archive ouverte pluridisciplinaire $\mathbf{H A L}$, est destinée au dépôt et à la diffusion de documents scientifiques de niveau recherche, publiés ou non, émanant des établissements d'enseignement et de recherche français ou étrangers, des laboratoires publics ou privés. 


\title{
The Role of Communicators in Innovation Clusters
}

\author{
Bettina Blasini (bsb25@cam.ac.uk) \\ Rani J. Dang (dang@gredeg.cnrs.fr) \\ Tim Minshall (thwm100@eng.cam.ac.uk) \\ Letizia Mortara (Im367@cam.ac.uk)
}

Bettina Sophie Blasini is a PhD student at the University of Cambridge under the supervision of Tim Minshall. She holds a Master of Arts in Mass Communication and Journalism from Ludwig-Maximilians University Munich and an MPhil in Innovation, Strategy and Organisation of Judge Business School Cambridge. Besides her studies, Bettina Sophie worked at the University of Munich and as a freelance journalist.

Rani Jeanne Dang is an Assistant Professor at the University of Nice Sophia-Antipolis, affiliated to CNRS, the National Centre for Scientific Research in France (GREDEG Research group) where she researches and teaches in the fields of innovation, entrepreneurship and strategy. She is also a Broman Research Fellow at the Institute for Innovation and Entrepreneurship, University of Gothenburg, Sweden. She holds a Ph.D in Management from University of Nice / CNRS and was also a visiting researcher at the University of Cambridge, UK and a project officer at the Pôle de Compétitivité SCS (Secured Communicating Solutions), the cluster-led innovation policy in France. Rani's main research interest is the development of small firms through collaborations in regional ecosystems of innovation.

Letizia Mortara is a Senior Research Associate at the Centre for Technology Management at the Institute of Manufacturing, University of Cambridge (UK). Her current interests and expertise include Open Innovation, Additive Manufacturing and Technology Intelligence. Letizia has a first degree in Industrial Chemistry from the University of Bologna (Italy). After working as a process/product manager for the IVM group specialised in coatings, stains and primers for wood, she moved to the UK where she gained her PhD in processing and process scale-up of advanced ceramic materials at Cranfield University.

Tim Minshall is a Senior Lecturer at the University of Cambridge Centre for Technology Management. His researches, teaches, writes and consults on the topics of open innovation, technology enterprise, the financing of innovation, and university-industry knowledge exchange. He is a non-executive director of St. John's Innovation Centre Ltd, Cambridge and a Visiting Professor at Doshisha University Institute for Technology, Enterprise and Competitiveness in Japan. He has a BEng from Aston University, and a PhD from Cambridge University Engineering Department. Prior to joining the University of Cambridge, he worked as an engineer, teacher, consultant, freelance writer and project manager in the UK, Japan and Australia. 


\begin{abstract}
Innovation clusters continue to be an important focus of economic development policies in many nations. Leading innovation clusters demonstrate that regional concentration strengthens the innovative capability and can lead to successful competitiveness on a global level, as demonstrated by regions such as Silicon Valley (US), Cambridge (UK) and Sophia Antipolis (France). However the successful creation of clusters still presents a challenge to policy makers as efforts to do so regularly fail. The development of innovation clusters has therefore received much academic and policymaker attention. While past research has examined a variety of factors as drivers for clustering effects, the role of communication within the cluster - and, specifically, the role of key individual communicators - in underpinning successful cluster development has received almost no academic attention. In this chapter, we will draw upon the relevant literature to develop a conceptual framework that will underpin research on this important topic by investigating the role of communicators in innovation clusters. Building on communication theories, the framework suggests that there are four influence-levels that shape and impact the role of communications in innovation clusters: the Individual Level, the Organizational Level, the Cluster Level and the Context. The interdisciplinary view on clustering effects contributes valuable insight to both communication studies and cluster theories. The framework developed within this chapter provides a structure to aid future research on the role of communicators within innovation clusters.
\end{abstract}

Blasini B. S., Dang R. J., Mortara L, T. Minshall "The Role of Communicators in Innovation Clusters"; in Strategy and Communication for Innovation, An Integrative Management View for Start-ups, Companies and Collaborative Networks in the Open Innovation Economy, 2nd edition, coord. Pfeffermann, N., Minshall, T., \& Mortara, L. (Eds.) forthcoming, 2014 


\section{The Role of Communicators in Innovation Clusters}

\section{Bettina Blasini, Rani J. Dang, Tim Minshall, and Letizia Mortara}

\section{Introduction}

Innovation clusters continue to be an important focus of economic development policies in many nations (Uyarra \& Ramlogan 2012). Leading innovation clusters demonstrate that regional concentration strengthens the innovative capability and can lead to successful competitiveness on a global level, as demonstrated by regions such as Silicon Valley (US), Cambridge (UK) and Sophia Antipolis (France). However the successful creation of clusters still presents "[..] a unique challenge to policy makers" as efforts to do so regularly fail (Clark 2013: 6). The development of innovation clusters has therefore received much academic (e.g. Porter 1998; Karlsson 2008) and policymaker (e.g. European Commission 2008; OECD 2012) attention. While past research has examined specialized supply and demand, collaboration and competition, the infrastructure and mobility of goods as crucial drivers for clustering effects, the role of communication within the cluster - and, specifically, the role of key individual communicators - in underpinning successful cluster development has received almost no academic attention.

Perceptions gathered from interviews ${ }^{1}$ in one of Europe's leading clusters indicates that this may be an important omission: "Public Communication is critical [..]. If it wasn't for the communication, the cluster wouldn't exist. It is very important that people within the cluster talk to each other and that the cluster communicates with the outside world" (PR Consultant, Cambridge, UK). For complex clusters, which are characterized by diverse internal and external stakeholders, communication was seen by the same interviewee as the "segment that holds it all together". Gathering and sharing information, communicators build interrelations between the actors and create a communication network. "We joined up and connected the companies in the Cambridge area and we also connected those companies with trade collaborators in other parts of the world. We are the catalyst for growth," explained an editor in chief of a newspaper in Cambridge. Connecting and informing relevant stakeholders, communicators describe their work as, in the words of one interviewee, "breaking down boundaries. That's the core of communication".

Such statements point to an important yet under-researched issue, which merits attention in order to enrich our understanding of how innovation clusters develop. In this chapter, we will draw upon the relevant literature to develop a conceptual framework that will underpin research on this

\footnotetext{
${ }^{1}$ Eight professional communicators working in the Cambridge (UK) cluster were interviewed as part of an on-going research project in April-May 2013.
} 
important topic by investigating the role of communicators in innovation clusters. Building on communication theories, the framework suggests that there are four influence-levels that shape and impact the role of communications in innovation clusters: the Individual Level, the Organizational Level, the Cluster Level and the Context. The interdisciplinary view on clustering effects will contribute valuable insight to both communication studies and cluster theories. On a theoretical level this study provides a strong foundation for further research in the field of innovation communication and on a practical level it identifies aims and strategies of communicators in innovation clusters.

\section{Economic and Sociological Cluster Theories}

The geography of innovation shows a clustered economic landscape, characterized by a regional concentration of innovative capability. Established cluster theories discussed this phenomenon from different perspectives and identified factors, which support the local agglomeration. Marshall (1890, 1920) introduces the notion of external economies, an environment characterized by skilled labour, specialized goods, face-to-face contact and trust, which enables spill-overs and sparks innovative activity. Porter $(1990,1998,2000)$ highlights the importance of external value and identifies supply and demand conditions, competition and collaboration and the context of the firm as most important for innovative capability. Krugman $(1994,1998)$ focuses on the dynamics of resource allocation across activities and location by identifying tangible and intangible goods that shape a complex economic environment. The research by Marshall, Porter and Krugman established a strong foundation to understand the dynamics of clustering-effects and influenced the academic perspective on how innovation takes places. While these papers have mostly been discussed in terms of their economic contribution, they also imply the importance of sociological aspects. Discussing externalities, Marshall, Porter and Krugman refer to information gathering, knowledge sharing and the resulting relations between the actors (as summarized in Table 2.1).

\begin{tabular}{|l|l|}
\hline Economic Cluster Theories & Role of communication \\
\hline Marshall $(\mathbf{1 8 9 0 , 1 9 2 0 )}$ & $\begin{array}{l}\text { Marshall introduces the idea of knowledge- } \\
\text { spillover, which is based on the face-to-face } \\
\text { contact of the people. According to Marshall, } \\
\text { individuals move from firm to firm and exchange } \\
\text { knowledge and ideas. }\end{array}$ \\
\hline Porter $(\mathbf{1 9 9 0 , 1 9 9 8 , 2 0 0 0 )}$ & $\begin{array}{l}\text { In his Diamond-Model, Porter discusses } \\
\text { knowledge about new innovations and early } \\
\text { perceptions of new possibilities due to the close }\end{array}$ \\
\hline
\end{tabular}




\begin{tabular}{|l|l|}
\hline Krugman (1994, 1998) & relationships between the actors. \\
\hline $\begin{array}{l}\text { Krugman's notion of centripetal forces can be } \\
\text { understood as external economies, which are } \\
\text { based on relationships and shared information. }\end{array}$ \\
\hline
\end{tabular}

Table 2.1: The Role of Communication in Economic Cluster Theories

The sociological factors, as shown in Table 2.1, are kept implicit within in the economic theories and are not explained in depth. This leads to a blurred understanding of sociological externalities based on interrelations, common knowledge and information spill-overs. Focusing on the characterisation of interrelations within a network and the resulting information gathering and sharing processes, sociological theories complement the economic perspective on cluster dynamics. Network Theory, Knowledge-Based View and Gatekeeper Studies provide a valuable insight to the research field as shown in Table 2.2 .

\begin{tabular}{|c|c|c|}
\hline $\begin{array}{l}\text { Sociological Cluster } \\
\text { Theories }\end{array}$ & Author & Role of communication \\
\hline \multirow[t]{2}{*}{ Network Theory } & Granovetter (1937) & $\begin{array}{l}\text { Close relationships that are characterized by strong } \\
\text { ties are more likely to share knowledge than those } \\
\text { who communicate infrequently or who are not } \\
\text { emotionally attached. Weak ties, i.e. } \\
\text { acquaintances, support the diffusion of knowledge, } \\
\text { the creation of new opportunities and the } \\
\text { emergence of new collaborations. }\end{array}$ \\
\hline & Burt $(1992,2001)$ & $\begin{array}{l}\text { Structural holes define potential connections } \\
\text { between units that are not connected and lead to } \\
\text { non-redundant information, as the sources are } \\
\text { more additive than overlapping. }\end{array}$ \\
\hline \multirow[t]{2}{*}{ Knowledge Based View } & Polanyi (1958) & $\begin{array}{l}\text { Tacit knowledge can be understood as "not } \\
\text { codified" knowledge. As it defies easy articulation } \\
\text { or codification, it is difficult to exchange over long } \\
\text { distances. }\end{array}$ \\
\hline & Asheim \& Gertler & Tacit knowledge depends on shared conventions \\
\hline
\end{tabular}




\begin{tabular}{|l|l|l|}
\hline & (2006) & $\begin{array}{l}\text { and norms that have been fostered by a common } \\
\text { institutional environment and relies on mutual } \\
\text { language and communication codes. Thus it is } \\
\text { transferred through face-to-face interactions } \\
\text { between individuals }\end{array}$ \\
\hline Gatekeeper Studies & $\begin{array}{l}\text { Dang, Mortara, } \\
\text { Thomson \& } \\
\text { Minshall (2011) }\end{array}$ & $\begin{array}{l}\text { To access tacit knowledge and context-laden } \\
\text { information, "listening posts" are created in order } \\
\text { to build channels inside and outside the cluster. }\end{array}$ \\
\hline Lezaric, Longhi \& & $\begin{array}{l}\text { Gatekeepers are characterized by three functions: } \\
\text { Thomas (2008) }\end{array}$ & $\begin{array}{l}\text { 1. To search information from external sources } \\
\text { 2. To transcode and translate the meaning of } \\
\text { information. }\end{array}$ \\
\hline $\begin{array}{l}\text { 3. To transfer information and to disseminate } \\
\text { accumulated and local knowledge }\end{array}$
\end{tabular}

Table 2.2: The Role of Communication in Sociological Cluster Theories

Both economic and sociological cluster theories highlight the importance of networking, knowledge gathering and information sharing. While economic theories imply such action as given processes, sociological theories acknowledge a deliberate and organized way of connecting and communicating. Gatekeeper studies point to the importance of specific actors managing information in order to build relationships inside and outside the cluster. Communication studies have a long tradition in analysing actors who pursue these aims on a professional basis, but have never been applied to the study of clusters. This discipline opens new perspectives of analysing and understanding cluster processes. Thus the next section will introduce the different role of communicators as discussed in communication studies.

\section{Communication studies}

Originally communication studies focused on journalism, which has been defined as public mass communication that targets a broad and heterogeneous audience in order to inform (Pürer 2003: 75). Over the last century, corporate communication, especially public relations, gained a lot of academic attention. Public relations can be also understood as public communication but addresses defined stakeholders to pursue specific messages. In their interplay, journalism and public relations target a broad audience and thus shape and influence the public opinion. The following two sections 
introduce the actors in these professions:

\section{Journalists}

The understanding of the journalists' role has been changing over time in academic research. Based on the News-Bias studies, early research regarded journalists as powerful "gatekeepers" who decide what is newsworthy according to their own principles. Further studies took social aspects into account: gatekeeping as part of a profession, influenced by social norms and values, political and social standards and criteria of production such as time pressure or constrained wordcount. Research on news factors and news values strengthened the perspective that journalists are not isolated actors, but part of a social process that is influenced by journalism routines.

Targeting the public, journalism has always been attributed a strong impact on society and has been discussed in terms of its framing, priming and story-telling potential. Recent research assumes that mass media structures knowledge and opinions of the recipients and define what they perceive as important (Rössler 1997). Thus journalists do not influence what recipients think, but what they think about.

\section{Public Relations consultants}

Discussing the impact of journalists on the public opinion, public relations has become prominent in communication studies. Public relations is persuasive communication following a certain strategy to evoke publicity by both functioning as a source for journalism and targeting stakeholders directly. Addressing journalism public relations consultants have been understood as influential actors in the dynamics of public communication. Ever since Bearns (1985) stressed that public relations consultants determine journalism through timing and content, the relationship of influence has been a recurring theme in communication research. More recent studies show a rather balanced relation: the intereffication model by Bentele, Liebert and Seeling (1997) analysed the daily collaborations between public relations consultants and journalists and showed a bilateral give and take interrelation (Bentele, Liebert \& Seeling 1997). Based on these results, they created the model of intereffication. "Intereffication" stems from the Latin terms "inter" and "efficare" and means "to enable each other". While journalists needs the basic information of public relations, public relations benefits by the broad and heterogeneous audience of journalism and its significance. Therefore analysing public communicators both journalists and public relations consultants should be taken into account.

\section{Innovation Communication}


Understanding the traditional roles of communicators in communication studies offers valuable insight to the role of communicators in innovation clusters. Going back to Porter, clusters can be understood as "geographic concentrations of interconnected companies, specialized suppliers and service providers, firms in related industries and associated institutions (e.g. universities, standard agencies, and trade association) in particular fields, that compete but also cooperate" (Porter 2000: 253). Consisting of heterogeneous members, clusters are characterized by many communicators taking part in public communication, pursuing different aims and strategies. To understand the role of communicators in innovation clusters, the young and developing research field innovation communication provides significant contribution.

Introducing the concept of "Innovation Journalism" in 2004, Nordfors sparked the academic debate about how communication might affect innovation innovations or innovation clusters (Nordfors 2004a; Nordfors 2004b; Nordfors \& Ventresca 2006; Nordfors \& Uskali, Nordfors 2009). His research highlights the leverage of communication in two ways: Journalists start a public discussion and thereby create a public agenda. Furthermore journalists may explain complex innovations and create meanings.

Building on Nordfors' research, Zerfass (2005) introduces a broad view on communication, which includes not only journalism but also public relations and interpersonal communication to meet the challenges of innovation clusters. According to Zerfass the complexity of innovation clusters calls for manifold public and bilateral relations driven by communication. Innovation journalists as defined by Nordfors play an important role in facilitating information flow, which allows collaborations and the identification of entrepreneurial opportunity. Innovation public relations consultants aim to systematically plan, implement, and evaluate communication strategies in order to create an understanding of and trust in innovations. Finally innovation-related leadership communicators seek to influence attitudes towards innovations by mediating meaning in asymmetrical, social relations (Zerfass 2005: 11).

Pfeffermann (2011) highlights the strategic perspective on communication by discussing innovation communication as a cross-functional dynamic capability of an innovative company or cluster. As defined by Teece et al. (1997) dynamic capabilities are the firm's capacity to integrate, build and reconfigure internal and external resources and competences to address and shape rapidly changing business environments (Teece, Pisano \& Shuen 1997: 516). Pfeffermann shows that communicators can achieve this aim by introducing ideas and concepts, generating and highlighting context-issues, presenting the organization's innovative capability, building up new stakeholder schemata or modifying existing ones (Pfeffermann 2011: 263). Though Pfeffermann's research is only valid for 
public relations consultants - journalists aim for neutral information - it gives new and valuable insight to the research field of innovation communication.

Nordfors, Zerfass and Pfeffermann provide important contributions from different perspectives to the research field innovation communication. By highlighting the potential of communicators in innovation clusters their studies complement cluster theories on different levels.

In summary, according to Nordfors, Zerfass and Pfeffermann communicators may:

- Name and explain innovations (Nordfors 2004a)

- Create a public news agenda (Nordfors 2004b)

- Formulate a shared vision of the cluster (Zerfass 2005)

- Connect stakeholders inside and outside the cluster (Zerfass 2005)

- Create collaborations and entrepreneurial opportunities (Zerfass 2005)

- Introduce new ideas and concepts (Pfeffermann 2011)

- Build new knowledge schemata and or modifies existing ones (Pfeffermann 2011)

- And thus creates and maintains a cluster's innovative capability (Pfeffermann 2011)

These highlighted issues point to the need for more research on the role of communicators in innovation clusters. The analysis of communicators requests an interdisciplinary approach to take both business and communication studies into account. In the next section the conceptual approach to analyse communicators will be introduced.

\section{Conceptual Approach}

Communication studies have a broad tradition in analysing communicators in various contexts. Its origins go back to sociological studies by Weber, Durkheim and Bourdieu who discussed action theory and identified the possibilities and limits of the individual's action. This can be seen as response to system theory, which dominated the field over a long period of time and drew attention away from the individual and towards field structures. Communication studies benefited from both research perspectives and developed complex perspectives on communicators, its personal potential of action and the influences by its environment. Based on the influential sociological studies, communication studies show different approaches to analyse the role of communicators by identifying the elements and composition of the "role". The interest of communication studies can be explained by the potential influence of the communicator's role on the content of news. Thus some approaches focus on the media content, yet offer a valuable basis to understand and identify influencing factors on the communicator and of the communicator. Table 5.1 summarises the 
influential communicator studies by Shoemaker and Reese (1991), Weischenberg (1992), Esser (1997) and Preston (2009).

\begin{tabular}{|c|c|}
\hline Conceptual Approach & fluence Levels and Categories \\
\hline $\begin{array}{l}\text { Shoemal } \\
\text { (1991) }\end{array}$ & $\begin{array}{l}\text { Individual Level: Personal aspects such as professional backgrounds and } \\
\text { experiences, professional roles and ethics, personal attitudes, values and } \\
\text { beliefs and the power within the organization. } \\
\text { Routines Level: Routinized and repeated practises, which can be viewed as } \\
\text { both enabling and constraining. } \\
\text { Organizational Level: Organizational roles, organizational structure, } \\
\text { organizational policies. } \\
\text { Extra-Media Level: Institutions in society, government, advertisers, public } \\
\text { relations, influential news sources, interest groups, and other media } \\
\text { organizations. } \\
\text { Ideological Level: Social interest and the construction of meaning. }\end{array}$ \\
\hline Weischenberg (1992) & $\begin{array}{l}\text { Media-Actor: Demographic Data, social and political opinions, perception } \\
\text { of the role, image of Recipient, professionalism and socialization. } \\
\text { Media-Message: Origin of information, reference groups, patterns of } \\
\text { presentation and news, construction of reality effects and retroactive } \\
\text { effects. } \\
\text { Media-Institution: Economical imperatives, political imperatives, } \\
\text { organisational imperatives and technological imperatives. } \\
\text { Media-System: Societal conditions, historical and legal foundations, } \\
\text { communication policy, professional and ethical standards. }\end{array}$ \\
\hline Esser (1997) & $\begin{array}{l}\text { Individual Level: Subjective values, political attitudes, work motivation, } \\
\text { self-perception, professionalism and demographic data. } \\
\text { Organizational Level: Job profiles and practices, organisational structure, } \\
\text { distribution of competences, work processes, control and technology }\end{array}$ \\
\hline
\end{tabular}




\begin{tabular}{|l|l|}
\hline $\begin{array}{l}\text { within the media organization. } \\
\text { Legal-Normative and Economic Level: Economic conditions of the media } \\
\text { market, press law, self-control in media, ethic foundation, trade unions and } \\
\text { associations, education of journalists. } \\
\text { Historic-Cultural Level: Freedom of the press media history, perception of } \\
\text { the press, journalistic tradition, understanding of objectivity, political } \\
\text { culture and socio-political conditions. }\end{array}$ \\
\hline Preston (2009) & $\begin{array}{l}\text { Individual Level: Personal characteristics, background, values of the } \\
\text { communicator, definitions and perception of their professional roles. } \\
\text { Media Routines: Taken-for granted institutional practices and norms, that } \\
\text { frame and shape how individuals work and function within complex } \\
\text { settings. } \\
\text { Organizational Influences: Organizational values, strategic goals, policies } \\
\text { and power structures of the company. } \\
\text { Political-Economic Factors: Political and economic culture, distribution of } \\
\text { power in society. }\end{array}$ \\
\hline
\end{tabular}

Table 5.1: Conceptual Approach on the Role of Communicators

\subsection{Theoretical Foundation}

The Hierarchy of Influences approach by Shoemaker and Reese (1991), the Zwiebelmodell by Weischenberg (1992), the Integrative Multi-Level Model by Esser (1998) and the Clusters of Influences approach by Preston (2009) contribute valuable insight to the influences on the role of communicators. Though they follow different research interests, they show similar patterns and recurring sets of structures as summarized in Table 5.2:

\section{Levels of Influence

\section{\& Reese}




\begin{tabular}{|ccccc|}
\hline Individual Level & $\checkmark$ & $\checkmark$ & $\checkmark$ & $\checkmark$ \\
\hline Media Routines Level & $\checkmark$ & $\checkmark$ & & \\
\hline Organizational Level & $\checkmark$ & $\checkmark$ & $\checkmark$ & $\checkmark$ \\
\hline $\begin{array}{c}\text { Political \& Economic } \\
\text { Level }\end{array}$ & $\checkmark$ & $\checkmark$ & $\checkmark$ & $\checkmark$ \\
\hline $\begin{array}{c}\text { Culture \& Ideology } \\
\text { Level }\end{array}$ & $\checkmark$ & & \\
\hline
\end{tabular}

Table 5.2: Structure of Influence Levels

As shown in Table 5.2, influence approaches usually draw on four or five influence levels to cover the complex power structure in the communication field. Whether four or five levels are identified, depends on the structuration of influence levels: While Shoemaker and Reese (1991) and Preston (2009) differentiate between economic and cultural background, Weischenberg (1992) combines these influences in a Media System level. Furthermore, the level Media Routines appears in most of the approaches as a level on its own, only Esser mentions routines in terms of patterns and structures in the context of the Organizational Level. Besides these minor distinctions, the approaches show a common structure:

1. Individual Influences

2. Organizational Influences

3. Communication System Influences

4. Cultural, political, economical background Influences

The hierarchical order of the levels also shows the same composition: The Individual Level is in the centre of influence structure, embedded in the Organizational Influence Level, covered by the System Influences, surrounded by the Macro Influence Level, such as cultural, political and economical conditions. While the early studies by Shoemaker and Reese (1991) and Weischenberg (1992) do not explicitly take interrelations between the levels into account, the more recent approaches by Esser (1998) and Preston (2009) highlight the reciprocal influences between the levels. According to Esser, the levels must be understood as "open" and not as "closed" systems (Esser 1998: 33).

To express in which context each of the levels works, graphic models provide important insight to the dynamic complexity of the communication field: By visualising, models simplify and structure the influences. Furthermore they create a profound foundation for an empirical analysis as they define the relevant factors and point out to interrelations. In the next section, a new model will be created 
in reference to the established models in order to build a theoretical framework for the analysis of communicators in innovation clusters.

\subsection{Creation of a Conceptual Framework}

The research on communicators in innovation clusters requires a new and specific framework. Unlike the frameworks discussed earlier, which focus on journalism only, this research includes different kinds of communicators to meet the challenges of innovation clusters. This points to the need for an interdisciplinary understanding of influence levels and categories. The framework proposed in Figure

\section{3 classifies four influence levels:}

1. Individual Level

2. Organizational Level

3. Cluster Level

4. Context

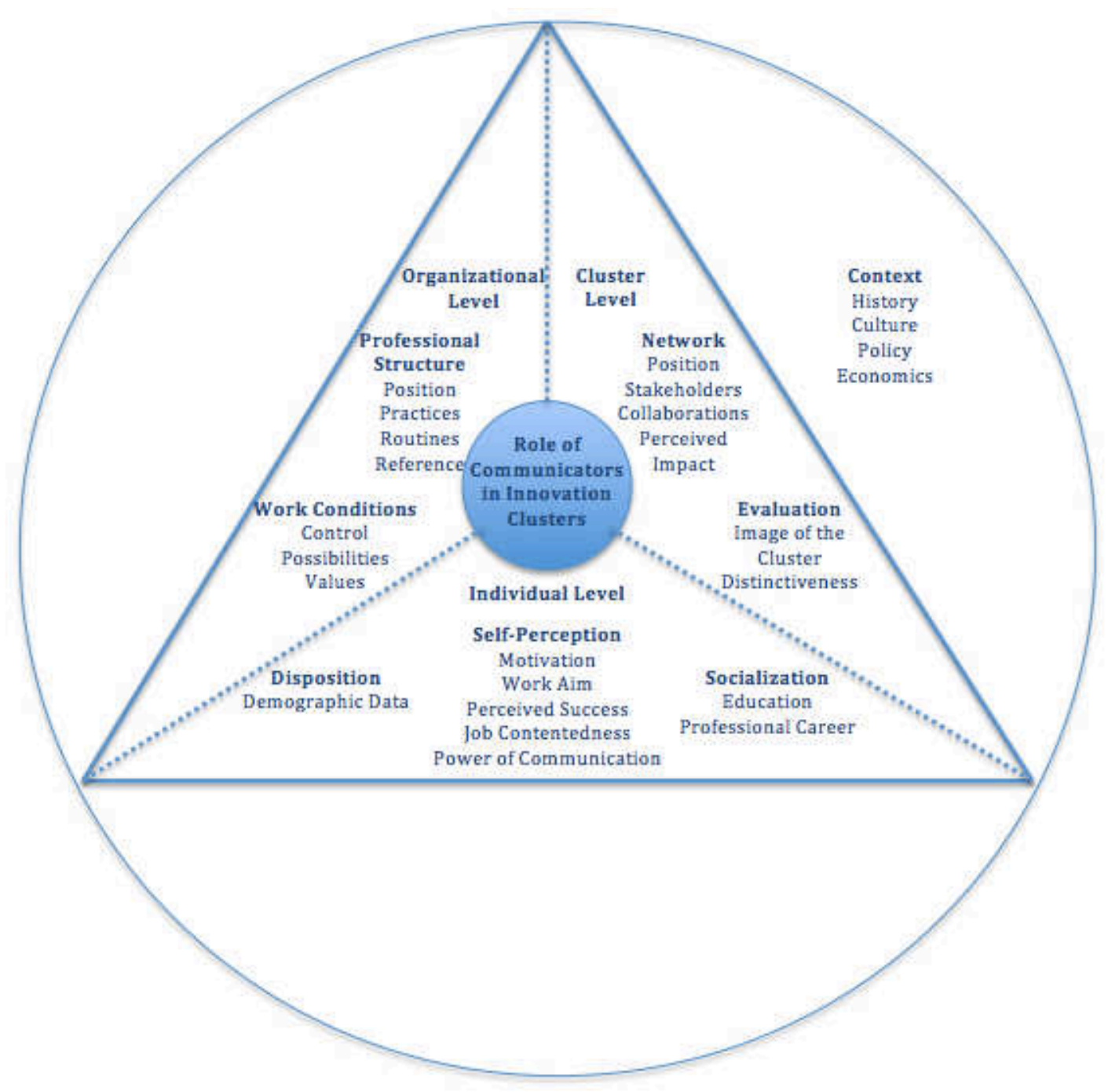

Figure 5.3: The Role of Communicators in Innovation Clusters 
The centre of the model shown in Figure 5.3 positions the research interest of the study, the role of communicators in innovation clusters. This role is influenced by the levels evolving around it: The individual influences, the organizational influences and the cluster influences. Graphically these influence levels are structured in a tetrahedron, which visualizes the reciprocal interaction between them. The openness of the levels is highlighted by the dotted lines that separate the levels. This visualization overcomes the problems of hierarchy as the influence levels take place on the same levels and therefore all interact. This interaction takes place in front of a societal background, which surrounds the influence-levels and the role of the communicator. It indicates that everything takes place in a certain context that has been established by various factors, such as historical, cultural, political and economical conditions, which have to be taken into account. In the following section each level will be explained in detail.

\section{Individual Level}

The Individual Level deals with the personal and unique attributes of the communicators. This level appeared in all models discussed earlier, as it covers important information about the personal position of the interviewees and thus builds the foundation to understand their ideas throughout the whole study. As the level implies various attributes, the model suggests three categories: Disposition, Socialization and Self-Perception. Disposition covers the demographic data, such as gender and age. Socialization also refers to individual attributes, covering the communicator's education and professional career. This category provides information on the interviewee's background and thus creates a deeper understanding for the communicator's position nowadays. Besides individual facts as dispositions and socialization, the Individual Level also covers the category Self-Perception. This category structures complex aspects of individual perceptions regarding the interviewee's role. Work motivation will provide valuable insight to the attitudes and expectations of the communicator. Closely linked is the definition of the work's aim, which identifies beliefs and ideas of the profession in general. Subsequently it is very interesting to analyse the perceived success of these aims to check the broad aspirations with the reality. This leads to the next aspect, the job contentedness, which deals specifically with the satisfaction in the profession and links back to realization of aims and motivations. Finally, the category Self-Perception points out to the importance of the perception of the power of communication. This aspect completes the idea about their profession, what they want to do, what they plan to do, if and how they achieve it and what greater power they might hold. As discussed in the literature review, the individual communicator has been seen as very influential in terms of creating a news agenda. Though the attributes and attitudes of the communicator is crucial, research pointed to the importance of the organizational setting of the communicator. Thus the next influence level will refer to the organizational categories and influence factors in detail. 


\section{Organization Level}

The Organization Level is also a strong component in the established models as it puts the individual in a context. The organization is the closest environment of communicators and frames their role strongly. Thus the level is distinguished into two categories, the Professional Structure and the Work Conditions. The professional structure first analyses the position of the communicator within the organization. That implies the understanding of the hierarchy structures and power relations within the given company. The identification of the position leads to the professional practices. The description of the daily activities provides valuable insight to the work of communicators and in which ways they might influences their role. The professional practices are closely linked to professional routines, which can be understood as both enabling and constraining. Analysing practices and routines, the reference groups of the communicators play a crucial role in different ways: as origins of information sources, as guidance in terms of professional capabilities but also as peer group pressure. Thus, reference groups have an impact on the role of communicators and should be analysed in the organizational context. Building on the findings of the category Practices, the category Work Conditions investigates how the quality of the work is perceived by the communicators. This category implies internal control, which could be developed trough hierarchal structures, peer pressure or organizational tendencies. However the possibilities and perceived freedom will also be analysed. The organizational atmosphere is much influenced by constraints and tolerance, and leads to the professional values that characterize a company. Values are a broad field and could be based on a journalistic education, organizational codes or general ethic norms that influence the organizational context. In sum the Organizational Level acknowledges that the communicators work in an organizational context that shapes and conditions their professional role. The research interest requests to understand the role of communicators also in a broader context, which impacts both individual and organization: the cluster.

\section{Cluster Level}

The Cluster Level is highly specific to this research interest, as it has not been discussed in communication studies before. While the models summarized earlier in section 5 focus on communication structures, such as media-institutions or the journalism field, this study takes place in a very distinctive environment: innovation clusters. This requests distinctive categories, which characterize - and thus analyse - the specifics of clusters. Applying a journalistic model to a business research field, previous models only benefit in terms of level analysis. To identify relevant categories for the Cluster Level, the cluster theories provide valuable contributions. As discussed in the literature review, the benefit of clusters lies in the network structure, which makes information flow 
and knowledge spillovers possible. Thus the Network is the first categories of the Cluster Level. This category refers to the interrelations and connections in terms of communication. First of all, the position in a network is influential for the role of communicators. Whether they are located centrally or rather distanced might impact the way they communicate. The position is connected with the important role of stakeholders: it is important to analyse who the stakeholders of the relevant communicators are and how they work with them. Also, if there are different communication strategies for each stakeholder could be very interesting. Bearing in mind the insights from the literature review, which identifies internal and external stakeholders of clusters, communicators can be seen as central actors who gather and spread knowledge. At this point it is very interesting to analyse the perceived success of their work: the perceived impact. How the communicators perceive their communication strategies are influencing their stakeholders, provides interesting insight to their professional role and evaluates their work experience. This leads to the second category of the Cluster Level, the Evaluation of the cluster. In this category, the perceived image of the clusters will be analysed. The image communicators have about a cluster will influence their behaviour, their opinions - their role. While the image can be created by other people's views, the second aspect only measures the individual opinion about the cluster. Analysing the distinctiveness from the communicator's point of view completes the evaluation as this aspect summarizes the perceived most important characteristics about the cluster and thereby reveal the personal "image".

Defined as regional agglomeration, clusters are influenced by their specific environment. This environment must be understood as broad background which influences not only the cluster but also the organizations and actors of the cluster. Thus it is important to set the so far identified levels of influence in a certain context.

\section{Context}

The three influence levels Individual Level, Organizational Level and Cluster Level are embedded in a specific Context. As explained earlier, the context impacts the influence-levels and the role of communicators in innovation clusters. The Context is identified as history, culture, policy and economics. These conditions are highly specific to geographic areas and frame the cluster, organizations and actors. The history factor examines the historical evolution of the cluster and takes important milestones into account. History is closely linked to further factors, namely culture, policy and economics. While history focuses on the development of a cluster, the culture factor looks at cultural environment of the cluster, for example the relation to universities and research institutions. The policy factor investigates how political decisions and support influences the cluster and shapes its situation. Political initiatives might lead to financial support, which will be examined by the factor economics. This latter factor concentrates on the financial situation and external support. The 
Context is important for the cluster, the organization and the actors and conditions the role of communicators in innovation clusters.

Together, the Individual Level, the Organizational Level, the Cluster Level and the Context create a valuable framework to analyse and understand the role of communicators in innovation clusters. Taking various levels and perspectives into account, the framework offers a strong foundation for further studies, which will be discussed in the following section.

\section{Conclusions}

The preceding sections brought together a diverse body of academic literature on cluster theories and communication studies in order to find interrelations between the two research fields. The classic economic cluster theories by Marshall $(1890,1920)$, Porter $(1990,1998,2000)$ and Krugman $(1994,1998)$ indicate the importance of communication, which informs but also connects actors inside and outside the cluster. While economic cluster theories refer to communication as given spillovers, sociological cluster theories acknowledge communication as an organized, deliberate process and thus complement the economic theories. The insights of Network Theory (Granovetter 1937, Burt 1992), Knowledge-Based View (Polany 1958, Asheim \& Gertler 2006) and Gatekeeper Studies (Lezaric, Longhi \& Thomas 2008) highlight the importance of communicators who build connections to gather and share information. While there is no research on communicators in innovation clusters, the young and developing research field innovation communication discussed by Nordfors (2004a, 2004b, 2009), Zerfass (2005) and Pfeffermann (2011) offers valuable insight and strengthens the demand for further research on the role of communicators in innovation clusters.

To achieve this aim, a conceptual framework has been created based on established conceptual approaches by Shoemaker and Reese (1991), Weischenberg (1992), Esser (1997) and Preston (2009). Though these studies focus on different research interests, they share a common quest into the interrelation between a communicator and the context that influences in both constraining and enabling ways. As discussed in the literature review communicators are not isolated individuals but part of an organizational and social context. To analyse the role of communicators, the relevant variables are heterogeneous and complex. The discussed models identify different influence levels and allocate influence factors appropriate to the specific research question. Also this study's research interest requested an unique conceptual framework to take the specification of innovation clusters into account. The tetrahedron-shaped framework identifies four influence levels: the individual level, the organizational level, the cluster level and the context which cover influence factors that shape and condition the communicator. The framework offers a strong foundation to investigate the role of 
communicators in innovation clusters.

This study addresses an unexplored interdisciplinary research area at the interface of communication and business studies and thus makes a series of academic and practical contributions.

\section{Innovation Communication}

Innovation communication is a new research field, which developed over the last decade. So far, research concentrated on innovation communication in terms of either innovation journalism or innovation communication on a corporate level. This research focuses on communication at a cluster level and therefore views innovation communication from a complex perspective: a cluster's communication is published by many different actors in different positions, pursuing different aims with different strategies. While previous communicator studies focused on a specific profession in public communication, this study includes different professions, which create the public message of a cluster. This approach allows the comparison of different professional positions and will make patterns visible. The inclusion of heterogeneous professions also allows the analysis of interaction. As discussed in the literature review, the interrelations between journalists and public relations consultants are intense and influential. Including everybody who engages in public communication about the cluster provides a holistic and comprehensive perspective on innovation communication.

\section{Cluster Theories}

Addressing innovation communication at a cluster level, this research contributes also to cluster theories. While both economic and sociological cluster theories refer to communication, the role of communicators stays implicit. Though sociological theories highlight connections and the management of information, the range of actors remain unclear. Investigating the people who make the message sheds light on a research angle, which has not been explored. The conceptual framework allows an understanding of the position of the communicators - who they are, what they do, what aim they pursue and which strategies they apply. This insight addresses the research gap between the assumed importance of communication in clusters and the missing data on it. The conceptual framework offers a valuable foundation for empiric research on the role of communicators in innovation clusters. The formulated categories, influence factors and their interrelation lead to a systematic structure for a qualitative interview guideline with relevant communicators. The results will establish how communicators connect in clusters, how they gather knowledge and share information and thereby create certain roles of communicators. Understanding the meaning of communicators will contribute valuable insight to classic cluster theories in terms of clustering dynamics. In addition to established cluster factors such as specialized supply and demand, 
collaboration and competition and the infrastructure and mobility of goods, communicators and their information networks should also be seen as crucial drivers for a cluster's development. Based on this understanding, further future research will be able to focus on the impact of communicators on the cluster's success and investigate causal effects on a quantitative basis. It will be interesting to compare different clusters in different developmental stages and in different locations to make similarities and differences visible.

\section{Practical Contributions}

This understanding provides valuable practical implications. Innovation clusters are based on the premise of interrelations and common knowledge and demand the creation and maintaining of a network of information inside and to the outside of the cluster. This points to three major aims for communicators:

1. Create connections and dialogue with internal stakeholders

2. Create interrelations and communication with external stakeholders and the outside world

3. Create a common language

Internal communication is crucial to connect the members within a cluster, to create a shared environment and a common vision. Only if members are connected and talk to each other will collaborations and entrepreneurial opportunities be possible. Knowledge spill-overs are rarely coincidence but based on a frequent dialogue between actors. As one journalist of one of the Cambridge High Tech Clusters explains "We actually joined up companies in the business community. We helped them collaborate with one another. Before you would have had companies operating in isolation. But you have got to have networks and connections. And we formed that role by publicizing companies and their role and what they were doing. We acted as catalyst for collaborations." It shows the important aim of communicators to connect and relate members of the cluster and thereby create a vibrant community. This practical insight refers back to cluster theory and provides valuable contribution to the studies of Marshall, Porter and Krugman who implied the importance of collaboration and shared knowledge by indicating the role of communication. Only if the cluster's members are aware of their environment, collaborations and entrepreneurial opportunities arise.

Furthermore external communication plays an important role as it connects the cluster to the outside world and allows collaborations with other clusters. External communication also has a representative role, aiming to attract potential members or financial supporters. A public relations consultant in Cambridge explained: "For Cambridge and the Cluster, to get this information out there 
is really key because you have people from around the world that are coming to Cambridge to look at it, and some are coming here to invest, that's because they are hearing about it, they are hearing the positive news. This is one of the key places in the world. If we didn't communicate that would they think to come to Cambridge? It's really important to get that message across". The strategic communication to the outside attracts attention from all over the world and thus positions the clusters in a global competition. This result can be drawn back to theoretical position of gatekeeper studies as discussed by Dang, Mortara, Thomson \& Minshall (2011) and Lezaric, Longhi \& Thomas (2008), who highlight the importance of creating channels not only inside but also outside the cluster. By representing the cluster to the outside world, communicators attract potential members and financial supporters.

To communicate successfully to the inside and the outside of the cluster, communicators have to create a common language by explaining complex innovations in order to make them accessible to a broader audience. A public relations consultant in the Cambridge cluster describes this process as "translation": "This is translation. The raw material compared to what is then written, you have to translate what can be something quite complex and put it into language. That is part of the communication, getting the language right that you are not dumbing down the technology or the invention but in that you are still caring up consistent messaging so that people will pick up and start to understand." Only by means of public communication, internal and external stakeholders will be able to comprehend unknown innovations. Communicators have to make sure that the message is consistent and understandable so that it reaches the recipients successfully. This has been discussed by Nordfors (2004a, 2004b) in terms of journalism. Anecdotal evidence shows that also public relations consultants are aware of the importance of "translation" and pursue this aim and thus contributes to the research on innovation communication.

The identification of communicators' aims in innovation clusters make strengths and weaknesses of clusters visible and point to specific improvements in terms of internal and external communication and the creation of a common language. Understanding the role of communicators in innovation clusters provides first insights to the interrelations of communication and a cluster's development. This understanding allows future research on the dynamics of communication and creates a new perspective on the evolution of innovation clusters. 


\section{Literature}

Asheim, B.T. \& Gertler, M. S. (2006): The Geography of Innovation. In: J. Fagerberg, Mowery, D.C. \& R.R Nelson: The Oxford Handbook of Innovation. Oxford: Oxford University Press. 291-317.

Baerns, B. (1985): Öffentlichkeitsarbeit oder Journalismus. Zum Einfluß im Mediensystem. Köln: Verlag Wissenschaft und Politik.

Bentele, G.; Liebert, T. \& Seeling, S. (1997): Von der Determination zur Intereffikation. Ein Integriertes Modell zum Verhältnis von Public Relations und Journalismus. In: G. Bentele \& M. Haller (eds): Aktuelle Entstehung von Öffentlichkeit. Akteure, Strukturen, Veränderungen. Konstanz: UVK. 225-250.

Burt, R. S. (1992): Structural Holes. Cambridge, MA: Harvard University Press.

Burt, R. S. (2001): The Social Capital of Structural Holes. In: M.F. Guillén, R. Collins, P. England \& M. Meyer (eds.): New Direction in Economic Sociology. New York: Russell Sage Foundation. 201-247.

Clark, J. (2013): Tech Country Report. Online:

http://admin.bvca.co.uk/library/documents/Tech_Country.pdf (13.05.2013)

Dang, R. J.; Mortara, L.; Thomson, R. \& Minshall, T. (2011): Developing a Technology Intelligence Strategy to Access Knowledge of Innovation Clusters. In: M. Hülsmann \& N. Pfeffermann (eds.): Strategies and Communications for Innovations. An Integrative Management View for Companies and Networks. Heidelberg: Springer.

Esser, F. (1998): Die Kräfte hinter den Schlagzeilen. Englischer und deutscher Journalismus im Vergleich. München: Verlag Karl Alber.

European_Commision (2008): Towards world-class clusters in the European Union: Implementing the broad-based innovation strategy. European Commission. SEC(2008) 263.

Granovetter, M.S. (1973): The Strength of Weak Ties. The American Journal of Sociology, 78 (6), 1360-1380.

Karlsson, C. (2008): Handbook of Research on Cluster Theory. Edward Elgar Publishing.

Krugman, P. (1991): Increasing Returns and Economic Geography. Journal of Political Economic Geography, 99 (3), 483-499.

Krugman, P. (1994): Complex Landscapes in Economic Geography. The American Economic Review, $84(2), 412-416$.

Lezaric, N.; Longhi, C. \& Thomas, C. (2008): Gatekeepers of Knowledge versus Platforms of Knowledge: From Potential to Realized Absorptive Capacity. Regional Studies, 42 (6), 837-852.

Marshall, A. (1890): Principles of Economics. London: Macmillan.

Marshall, A. (1920): Industry and Trade. London: Macmillan.

Nordfors, D. (2004a): The Role of Journalism in Innovation Systems. Innovation Journalism, 1 (7/8), 118. 
Nordfors, D. (2004b): The concept of Innovation Journalism. And a Program for Developing it. Innovation Journalism,1 (1), 1-14.

Nordfors, D. \& Ventresca, M. (2006): Innovation Journalism: Towards Research on the Interplay of Journalism in Innovation Ecosystems. Innovation Journalism, 3 (2). 1-18.

Nordfors, D. \& Uskali. T. (forthcoming): The Role of Journalism in Creating the Metaphor of Silicon Valley, 1-20.

Nordfors, D. (2009): Innovation Journalism, Attention Work and the Innovation Economy. A Review of the Innovation Journalism Initiative 2003-2009. Innovation Journalism, 6 (1), 1-46.

OECD (2012): Cluster Policy and Smart Specialisation. OECD Science, Technology and Industry Outlook 2012. OECD Publishing.

Pfeffermann, N. (2011): Innovation Communication as a Cross-Functional Dynamic Capability: Strategies for Organizations and Networks. In: M. Hülsmann \& N. Pfeffermann (eds.): Strategies and Communications for Innovations. An Integrative Management View for Companies and Networks. Heidelberg: Springer. 257-292.

Polany, M. (1958): Personal Knowledge: Towards a Post-critical Philosophy. London: Routledge \& Kegan Paul.

Porter, M. (1990): The Competitive Advantage of Nations. Harvard Business Review. 73-93.

Porter, M (1998): Clusters and the Economics of Competition. Harvard Business Review. 77-90.

Porter, M. (2000): Location, Clusters and Company strategy. In: G. Clark, M. Gertler \& M. Feldman (eds): Oxford Handbook of Economic Geography. 253-274.

Pürer, H. (2003): Publizistik- und Kommunikationswissenschaft. Ein Handbuch. Konstanz: UTB.

Preston, P. (2009): Making the News: Journalism and News Cultures in Europe. London \& New York: Routledge.

Rössler, P. (1997): Agenda Setting. Theoretische Annahmen und Empirische Evidenzen einer Medienwirkungshypothese. Opladen: Westdeutscher Verlag.

Shoemaker, P. J. \& Reese, S.D. (1996): Mediating the Message: Theories of Influence on Mass Media Content. Second Edition. White Plains, NY: Longman.

Teece, D.J.; Pisano, G. \& Shuen, A. (1997): Dynamic Capabilities and Strategic Management. Strategic Management Journal, 18 (7), 509-533.

Uyarra, E. \& Ramlogan, R. (2012): The Effects of Cluster Policy on Innovation. UK National Endowment for Science, Technology and the Arts (NESTA). Working Paper 12/05.

Weischenberg, S. (1992): Journalistik. Medienkommunikation. Theorie und Praxis. Medienetik, Medieninstitutionen. Opladen.

Zerfass, A. (2005): Innovation Readiness. Innovation Journalism 2 (8)1-27. 